\title{
New serpulid polychaetes from the Permian of western Sicily
}

\author{
Rossana Sanfilippo, Antonietta Rosso, Agatino Reitano, Alfio Viola, and Gianni Insacco \\ Acta Palaeontologica Polonica 63 (3), 2018: 579-584 doi:https://doi.org/10.4202/app.00448.2017
}

Two new tubeworms, "Serpula" calannai sp. nov. and "Serpula" prisca sp. nov. are described from the Permian limestone of the Sosio Valley, western Sicily. Both species possess large tubes with long free anterior portions circular in cross-section. All morphological characters, such as tube shape and ornamentation, as well as inner structure of the wall, even if barely visible due to diagenesis, are still preserved. These two new species increase the previously known diversity of the Permian serpulid community, which flourished at the shelf edge of the western sector of the Palaeotethys and disappeared thereafter. The likely Wordian age of these serpulids, and their presumed absence in younger rocks up to the Middle-Late Triassic, suggests reduction, or even extinction, of these reef-related serpulid taxa during the end-Guadalupian biotic crisis, before the end-Permian extinction.

Key words: Polychaeta, Serpulidae, tube morphology, reef community, extinction events, Palaeozoic, Permian, Italy.

Rossana Sanfilippo [sanfiros@unict.it], Antonietta Rosso [rosso@unict.it], and Alfio Viola [a.viola@unict.it], Department of Biological, Geological and Environmental Sciences, University of Catania, Corso Italia 57, 95129 Catania, Italy. Agatino Reitano [tinohawk@yahoo.it] and Gianni Insacco [g.insacco@ comune.comiso.rg.it], Museo di Storia Naturale di Comiso, Via degli Studi 9, 97013 Comiso, Italy.

This is an open-access article distributed under the terms of the Creative Commons Attribution License (for details please see creativecommons.org), which permits unrestricted use, distribution, and reproduction in any medium, provided the original author and source are credited. 
